\title{
Research on the Evaluation of Innovation Performance of Regional High-tech industry Based on Grey Relation Analysis
}

\author{
Peizhe Li \\ School of Business Shan Dong University of Political science and Law Jinan, China
}

\begin{abstract}
Scientific evaluation of the innovation performance of regional high-tech industry has an important impact on promoting the healthy development of high-tech industry and promoting regional economic growth. On the basis of constructing the index system of regional high-tech industry innovation performance evaluation, the index weight is determined based on the entropy weight method, and the gray correlation analysis method is used to evaluate and rank the regional high-tech industry innovation performance. The results show that there is a large gap in the innovation performance level of regional hightech industries in China, and the innovation performance level of coastal areas is higher, such as Guangdong, Jiangsu, Zhejiang and other provinces; the innovation performance level of western areas is lower, such as inner Ningxia, Xinjiang, Qinghai and other provinces. The evaluation result of this method is scientific and objective, and it has a good effect in high-tech industry innovation performance evaluation. The conclusion of this paper can provide corresponding enlightenment for the innovation activities of regional high-tech industries in China.
\end{abstract}

\section{Introduction}

High tech industry is the strategic leading industry of China's economy, which plays an important role in promoting the upgrading of industrial structure and the transformation of economic growth mode. The development level of high-tech industry is related to the comprehensive competitiveness of a country or region. In recent years, China's high-tech industry has developed rapidly and made great contributions to the development of China's economy. However, with the rapid development of high-tech industry, there are also many problems, such as the unbalanced regional development of high-tech industry, and there is still a big gap with developed countries in terms of technology level and technological innovation efficiency. As high-tech industry has the characteristics of technology and knowledge concentration, less consumption of resources and so on, the performance of technological innovation plays a more important role in guiding the development of industry, and also determines the overall development level of high-tech industry in various regions. Therefore, how to evaluate the innovation performance of regional high-tech industry scientifically and effectively is of great significance to the healthy development of regional high-tech industry.

Li Shoulin and others used the grey relation analysis and TOPSIS method to evaluate the innovation performance of listed logistics enterprises, analyzed the difference and weight of different enterprises in different indexes by entropy method, analyzed the correlation degree of each index and optimal value, and the performance of each enterprise under the two evaluation systems; Cao Yanling uses the weighted grey entropy correlation degree to replace the Euclidean distance measurement method in the ideal solution method, solves the problem that the abnormal value has a great influence on the evaluation result and the evaluation result changes with the grey correlation parameter, and gives an ideal solution method based on the weighted grey entropy correlation degree; Zhang Yong'an and others take the subordinate industry of high-tech manufacturing industry as the research object, and combines the entropy method to determine the investment index weight. The contribution degree of each innovation input factor to output is studied in depth by using grey relation analysis method; Sui Jun and others use grey relation analysis to empirically study the influencing factors of technology transfer of multinational companies on innovation performance of green innovation system of manufacturing industry in China; Liu Mingguang and others use grey relation analysis in grey system theory. In order to eliminate the influence of subjective factors and take full account of the inherent information of the evaluation matrix, the weight of each evaluation index is determined by using the approach ideal point method; Gao Changyuan and others set up the performance evaluation index system of knowledge innovation in high-tech virtual industry cluster By analyzing the types and levels of knowledge innovation, combined with the method of grey 
correlation analysis, constructed the performance evaluation model of cluster knowledge.

At present, researchers mainly from the construction of innovation index system, the selection of evaluation methods and so on. However, in general, the research on technological innovation performance is mainly concentrated on the industry and enterprise level. There are relatively few studies on the evaluation of regional high-tech industry innovation performance, and the construction of indicator system is not perfect, and the indicators involve too many areas and quantities, which is feasible for the evaluation of individual enterprises or some industries, but for the evaluation of high-tech industry innovation in different regions In terms of ability, some index data are difficult to obtain and are not feasible; some evaluation methods selected in the study are subjective, and the weight determination of the index contains larger subjective factors, and the evaluation methods need to be further optimized; the research on the differences in the performance of technological innovation in provincial high-tech industries is not deep enough. It makes the high-tech industry development planning and decision-making in many areas have certain blindness. In view of this, based on the research of scholars at home and abroad, this paper determines the index weight based on entropy weight method, and evaluates and ranks the innovation performance of regional high-tech industry by using grey correlation analysis method, and measures the regional innovation performance level of high-tech industry in China in recent years. To a certain extent, this study makes up for the deficiencies of the current research on technological innovation performance of high-tech industry, which can provide the basis for the formulation of relevant development policies of the government.

\section{Research theory and method}

Based on the entropy weight method, this paper determines the index weight, and uses the gray correlation analysis method to evaluate and rank the innovation performance of regional high-tech industry, and measures the regional innovation performance level of China's high-tech industry in recent years.

\subsection{Entropy weight method}

The methods to determine the index weight include subjective weight method and objective weight method. The subjective weight method includes expert scoring method, Delphi method, analytic hierarchy process, etc. The objective weight method includes principal component analysis method and entropy weight method, etc. Entropy weight method can use the inherent information of each scheme in the evaluation, and get the information entropy of each index through entropy value method. The smaller the information entropy is, the lower the degree of information disorder is, the greater the utility value of information is, and the greater the weight of index is. Entropy weight method makes the determination of index weight more objective and reasonable, avoiding the subjectivity of weight determination to a certain extent.

The specific steps of entropy weight method are as follows:

(1) Data standardization

Standardize the data of each index

Suppose $k$ indexes $X_{1}, X_{2}, \cdots X_{k}$, are given, where $X_{i}=\left\{x_{1}, x_{2}, \cdots x_{n}\right\}$. Assuming that the standardized value of each indicator data is $Y_{1}, Y_{2}, \cdots Y_{k}$, then:

$$
Y_{i}=\frac{x_{i j}-\min \left(x_{i}\right)}{\max \left(x_{i}\right)-\min \left(x_{i}\right)}
$$

(2) Find the information entropy of each index

According to the definition of information entropy in information theory, the information entropy of a group of data is:

$$
E_{j}=-\ln (n)^{-1} \sum_{i=1}^{n} p_{i j} \ln p_{i j}
$$

Among them, $p_{i j}=Y_{i j} / \sum_{i=1}^{n} Y_{i j}$, represents the contribution of the $i$ scheme under the $j$ attribute.

(3) Determine the weight of each index

According to the formula of information entropy, the information entropy of each index is calculated. Then the weight of each attribute is:

$$
W_{j}=\frac{d_{j}}{\sum_{j=1}^{n} d_{j}}
$$

Among them, $d_{j}=1-E_{j}$

\subsection{Grey relation analysis}

Grey theory is to establish the relationship between many factors in order to solve practical problems. It is necessary to distinguish the close factors of some fuzzy relations and find out the main characteristics and relations of these factors. Grey relation analysis is the main method in grey system theory, which aims to analyze the relation degree of various factors in the system. In this study, the gray correlation method is used to analyze, calculate the degree of relevance between the research object and the influencing factors of the object to be identified, and then analyze and determine the degree of influence between the factors or the contribution of the factors to the main behavior of the system through the degree of relevance. If the trends of the two factors are consistent, that is, the degree of synchronous change is high, the correlation between them is high, and vice versa. This method is also applicable to the number of samples and the regularity of samples, and the results are in good agreement with the actual situation.

The specific steps of grey relation analysis are as follows:

(1) Determine the dependent variable reference sequence reflecting the system behavior and the 
independent variable comparison sequence influencing the system behavior

The reference sequence of dependent variable is:

$$
X_{0}(k)=\left\{X_{0}(1), X_{0}(2), \cdots, X_{0}(n)\right\}, k=1,2, \cdots, n
$$

$n$ is the length index of the sequence.

The comparison sequence of independent variables is:

$$
X_{i}(k)=\left\{X_{i}(1), X_{i}(2), \cdots, X_{i}(n)\right\}, i=1,2, \cdots, m
$$

$\mathrm{M}$ is the number of comparison sequences.

(2) Dimensionless processing of reference sequence and comparison sequence

Due to the different physical meanings of the factors in the system, the dimensions of the data are not necessarily the same, which is not easy to compare, or it is difficult to get the correct conclusion when comparing. Therefore, in the process of grey correlation analysis, the dimensionless data processing is generally needed. The method includes initial value method, mean value method, etc. in this paper, the number series are basically monotonic, so the initial value method is used. The calculation formula is:

$$
x_{i}(k)=X_{i}(k) / X_{i}(1)
$$

(3) Calculation of correlation coefficient

The grey correlation coefficient formula is:

$$
\varepsilon_{i}(k)=\frac{\min _{i} \min _{j}\left|x_{0}(k)-x_{i}(k)\right|+\rho \max _{i} \max _{j}\left|x_{0}(k)-x_{i}(k)\right|}{\left|x_{0}(k)-x_{i}(k)\right|+\rho \max _{i} \max _{j}\left|x_{0}(k)-x_{i}(k)\right|}
$$

In the formula, $\rho \in(0, \infty)$, is the resolution coefficient, whose main function is to improve the difference between values. The smaller it is, the greater the resolution of the coefficient is, generally 0.5 .

(4) Calculate relevance

The method of arithmetic average is used to calculate the grey correlation degree, and the formula is as follows:

$$
r_{0 i}=\frac{1}{n} \sum_{k=1}^{n} \varepsilon_{i}(k)
$$

(5) Calculate weighted correlation

According to the weight $W_{j}$ obtained by the above entropy weight method, the grey correlation degree $r_{0 i}^{\prime}$ of the $i$ scheme:

$$
r_{0 i}^{\prime}=\frac{1}{n} \sum_{k=1}^{n} W_{j} \varepsilon_{i}(k)
$$

The grey correlation degree $r_{0 i}^{\prime}$ indicates the correlation degree between the scheme and the optimal reference sequence. The greater the grey correlation degree is, the closer the scheme and the optimal ideal value are, the stronger the competitiveness is.

\section{Data source and index selection}

\subsection{Data sources}

The data of this paper comes from the China Science and Technology Statistical Yearbook (2018) and China high tech Industry Statistical Yearbook (2018). The data of 30 provinces (cities, autonomous regions) in China are selected for analysis. Some data in Tibet are unavailable and are not listed temporarily.

\subsection{Index selection}

Due to the high technology content and complex innovation process of high-tech industry, the impact on its innovation performance involves many factors. The selected indicators should reflect the innovation ability of high-tech industry as much as possible. Refer to the relevant research of domestic and foreign scholars on the indicator system, select the following innovation performance indicators, as shown in Table 1:

TABLE I. PERFORMANCE EVALUATION INDEX OF REGIONAL HIGHTECH INDUSTRY INNOVATION

\begin{tabular}{|l|l|}
\hline $\begin{array}{l}\text { Index } \\
\text { number }\end{array}$ & Evaluating indicator \\
\hline$a_{1}$ & Profit \\
\hline$a_{2}$ & New product sales revenue \\
\hline$a_{3}$ & Number of patent applications for invention \\
\hline$a_{4}$ & $\begin{array}{l}R \& \text { D personnel equivalent to full time } \\
\text { equivalent }\end{array}$ \\
\hline$a_{5}$ & Internal expenditure of $R$ \& D funds \\
\hline
\end{tabular}

\section{Empirical analysis}

According to the five index variables of innovation performance of 30 provincial high-tech industries in China, based on the relevant data of high-tech industries in 2018, this paper uses entropy weight method to determine the index weight, and uses grey correlation analysis method to evaluate and rank the level of innovation performance of regional high-tech industries.

\subsection{Determine index weight}

According to the original data of the index, the weight of each index is calculated by entropy method. First, the original data is standardized. Then calculate the information entropy of each index.

(1) Find the information entropy of each index

According to the formula of information entropy, it is concluded that:

$$
E_{j}=(0.80,0.69,0.65,0.72,0.74)
$$

(2) Determine the weight of each index

According to the index weight formula, calculate the weight of each attribute, as shown in Table 2:

TABLE II. INDEX WEIGHT OF REGIONAL HIGH-TECH INDUSTRY INNOVATION PERFORMANCE EVALUATION 


\begin{tabular}{|l|l|l|}
\hline $\begin{array}{l}\text { Index } \\
\text { number }\end{array}$ & Evaluating indicator & weight \\
\hline$a_{1}$ & Profit & 0.14 \\
\hline$a_{2}$ & New product sales revenue & 0.22 \\
\hline$a_{3}$ & $\begin{array}{l}\text { Number of patent applications for } \\
\text { invention }\end{array}$ & 0.25 \\
\hline $\boldsymbol{a}_{4}$ & $\begin{array}{l}\text { R \& D personnel equivalent to full time } \\
\text { equivalent }\end{array}$ & 0.20 \\
\hline $\boldsymbol{a}_{5}$ & \begin{tabular}{l} 
Internal expenditure of $\boldsymbol{R} \&$ D funds \\
\hline
\end{tabular} & 0.19 \\
\hline
\end{tabular}

As can be seen from table 2, the weight of innovation performance evaluation index of high-tech industry is:

$$
W_{j}=(0.14,0.22,0.25,0.20,0.19)
$$

\subsection{Grey relation analysis}

(1) Determine reference sequence

First of all, the reference series reflecting the characteristics of the system behavior and the comparison series influencing the system behavior are determined. Since the regional advanced industry innovation performance evaluation indicators are all positive indicators, the maximum value of each indicator is selected as the reference sequence. Namely:

$X_{0}(k)=\{2324,208509696,59216,286010,11247028\}$

(2) Dimensionless index

Secondly, due to the different physical meanings of the factors in the system, the dimensions of the data are not necessarily the same, which is not easy to compare. Therefore, dimensionless processing is generally required in the analysis. The dimensionless method is the initial value method, and part of the data after dimensionless processing are:

$$
X_{i}(k)=\left[\begin{array}{lllll}
0.1711 & 0.0973 & 0.0847 & 0.0769 & 0.1193 \\
0.0670 & 0.0520 & 0.0181 & 0.0474 & 0.0606 \\
0.0535 & 0.0252 & 0.0121 & 0.0366 & 0.0388 \\
0.0262 & 0.0087 & 0.0028 & 0.0108 & 0.0120 \\
0.0088 & 0.0101 & 0.0026 & 0.0046 & 0.0087 \\
0.1049 & 0.0270 & 0.0255 & 0.0323 & 0.0367 \\
0.0605 & 0.0065 & 0.0070 & 0.0097 & 0.0086 \\
0.0189 & 0.0019 & 0.0039 & 0.0084 & 0.0053 \\
\ldots & \ldots & \ldots & \ldots & \ldots \\
\ldots & \ldots & \ldots & \ldots & \ldots
\end{array}\right]
$$

(3) Calculation of grey correlation coefficient

According to the correlation formula of grey correlation analysis, the grey correlation coefficient is calculated. Because of the length, only some grey correlation coefficients are listed here:

$$
\varepsilon_{i}(k)=\left[\begin{array}{lllll}
0.376 & 0.3562 & 0.353 & 0.3511 & 0.3619 \\
0.3487 & 0.3451 & 0.3371 & 0.344 & 0.3471 \\
0.3454 & 0.3388 & 0.3358 & 0.3414 & 0.3419 \\
0.339 & 0.335 & 0.3337 & 0.3355 & 0.3358 \\
0.3351 & 0.3353 & 0.3337 & 0.3341 & 0.335 \\
0.3581 & 0.3392 & 0.3388 & 0.3404 & 0.3414 \\
0.3471 & 0.3345 & 0.3346 & 0.3353 & 0.335 \\
0.3373 & 0.3335 & 0.334 & 0.3349 & 0.3343 \\
\ldots & \ldots & \ldots & \ldots & \ldots \\
\ldots & \ldots & \ldots & \ldots & \ldots
\end{array}\right]
$$

(4) Calculate weighted correlation

According to the index weight determined by entropy weight method and combined with grey correlation coefficient, the weighted correlation degree and ranking of regional high-tech industry innovation performance in China are calculated, as shown in Table 3:

\begin{tabular}{|c|c|c|}
\hline Region & Weighted relevance & Ranking \\
\hline Guangdong & 1 & 1 \\
\hline Jiangsu & 0.5789 & 2 \\
\hline Zhejiang & 0.497 & 3 \\
\hline Shandong & 0.4848 & 4 \\
\hline Fujian & 0.4699 & 5 \\
\hline Beijing & 0.4664 & 6 \\
\hline Sichuan & 0.4661 & 7 \\
\hline Henan & 0.4647 & 8 \\
\hline Shanghai & 0.4646 & 9 \\
\hline Hubei & 0.464 & 10 \\
\hline Anhui & 0.4613 & 11 \\
\hline Jiangxi & 0.4582 & 12 \\
\hline Hunan & 0.4577 & 13 \\
\hline Shaanxi & 0.456 & 14 \\
\hline Chongqing & 0.4557 & 15 \\
\hline Tianjin & 0.4537 & 16 \\
\hline Liaoning & 0.453 & 17 \\
\hline Hebei & 0.4506 & 18 \\
\hline Guizhou & 0.4479 & 19 \\
\hline Jilin & 0.4478 & 20 \\
\hline Guangxi & 0.447 & 21 \\
\hline Yunnan & 0.447 & 22 \\
\hline Shanxi & 0.4465 & 23 \\
\hline Heilongjiang & 0.4457 & 24 \\
\hline Gansu & 0.4456 & 25 \\
\hline Inner Mongolia & 0.4455 & 26 \\
\hline Hainan & 0.4452 & 27 \\
\hline Ningxia & 0.445 & 28 \\
\hline Xinjiang & 0.445 & 29 \\
\hline Qinghai & 0.4446 & 30 \\
\hline
\end{tabular}

TABLE III. WEIGHTED RELEVANCE AND RANKING OF INNOVATION PERFORMANCE OF REGIONAL HIGH-TECH INDUSTRIES

It can be seen from table 3 that by calculating the weighted grey correlation degree of regional high-tech industry in China, it is found that Guangdong, Jiangsu, Zhejiang, Shandong and Fujian are ranked in the top five provinces, indicating that the level of innovation performance in these provinces is relatively high, 
especially in Guangdong Province, which is significantly higher than other provinces. The innovation performance level of high-tech industry in Inner Mongolia, Hainan, Ningxia, Xinjiang, Qinghai and other provinces is relatively low, which is closely related to the geographical location of these regions and the foundation of high-tech industry.

\section{Introduction}

In this paper, the evaluation index system of innovation performance of regional high-tech industry is constructed, and the comprehensive evaluation of innovation performance level of regional high-tech industry in China is carried out by using the method of grey correlation analysis. The results show that there is a big gap in the innovation performance level of regional high-tech industries in China. The innovation performance level of eastern coastal areas is higher than that of western areas. Due to the weak foundation of high-tech industry and the difficulty of introducing scientific and technological talents, the overall innovation performance level in the western region is relatively low.

In view of the above conclusions, the following suggestions are put forward:

(1) Increase R\&D investment. The complexity and innovation of high-tech industry is high, and a very important factor of technological innovation is the investment of scientific research funds, especially in the growing enterprises, which need a lot of funds for innovation, and the lack of funds is often the main obstacle to the growth and development of high-tech enterprises. Therefore, high-tech enterprises should continue to increase the investment of scientific research funds on the basis of fully considering the cost of enterprises At the same time, we should explore multichannel fund-raising mechanism and technology talent introduction mechanism to lay a solid foundation for the rapid growth of enterprises.

(2) We will improve policy support and science and technology services. The government should create a good environment for the growth and development of the high-tech industry in various ways, such as constantly improving the rules and regulations of the high-tech industry innovation, providing policy guarantee for the industrial development; reducing the cost of the enterprise's technological innovation, improving the enthusiasm of the enterprise's technological innovation, and promoting the collaborative cooperation of the innovation subjects through tax preference and policy support; and it can improve the feedback speed and efficiency of information, promote the knowledge exchange and sharing within the system, and build a bridge for innovation cooperation among innovation subjects by establishing the innovation information service platform of high-tech industry, which plays an important role in promoting the overall innovation level of high-tech industry and promoting the rapid growth of industry.
Applying the grey relation analysis to the evaluation of innovation performance of regional high-tech industry, we can combine the quantitative and qualitative methods, aiming at a large number of uncertain factors and their interrelations, so that the original complex problems become more clear and simple, and the calculation is convenient, and the subjectivity of decision-makers can be excluded to a certain extent, and the conclusions are relatively objective, with certain participation Test the value. With the development and transformation of China's economy, the competition of high-tech industry is becoming more and more fierce. Nowadays, the competition of high-tech industry is essentially the competition of scientific and technological innovation. Only by continuously improving the level of regional high-tech industry innovation, can we truly form industrial advantages and promote the rapid and healthy development of China's high-tech industry.

\section{Acknowledgment}

This work was financially supported by: the National Natural Science Foundation Project(No.71573124), the Shandong Social Science Planning Research Project (No.14BGLJ07), the Humanities and Social Sciences Projects in Shandong Province(No.19-ZZ-GL-04), Scientific research project of Shandong University of political science and Law (No.2019Q03A).

\section{References}

[1] Li Shoulin, Zhao Rui, Chen Lihua. Innovation performance evaluation of logistics enterprises based on grey relation analysis and TOPSIS [J]. Industrial technology and economy, 2018,37 (04): 12-21

[2] Cao Yanling. Enterprise technological innovation performance evaluation based on weighted grey entropy correlation degree [J]. Technology economy and management research, 2015 (09): 4347

[3] Zhang Yong'an, Lu Ming. Evaluation of innovation efficiency of high-tech manufacturing industry and Research on the difference of factor input [J]. Science and technology progress and countermeasures, 2019,36 (16): 51-57

[4] Sui Jun, Bi Kexin, Yang Chaojun, Liu Gang. Influencing factors of innovation performance of green innovation system in manufacturing industry -- Based on the perspective of technology transfer of multinational companies [J]. Science research, 2015,33 (03): 440-448

[5] Liu Mingguang, Li Gaoyang. Research on innovation performance evaluation of regional innovation system in China [J]. Modern management science, 2011 (03): 72-74

[6] Gao Changyuan, Cheng Lu. Research on knowledge innovation performance model of high-tech virtual industry cluster based on grey relation analysis [J]. Library and information work, 2010,54 (18): 72-75

[7] Wang Xiaomeng. An Empirical Study on the performance evaluation of regional technological innovation policies from the perspective of correlation and grey correlation analysis $[\mathrm{J}]$. Scientific research management, 2014,35 (05): 38-43

[8] Wang Qingsong, Cheng Li. Grey correlation analysis of enterprise technological innovation and enterprise economic performance $[\mathrm{J}]$. China Science and Technology Forum, 2009 (12): 64-68

[9] Zhang Likun, Liu Xiaoli. Grey correlation analysis of influencing factors of urban innovation performance [J]. Science and technology management research, 2014,34 (01): 230-233 
[10] Pei Xiao, Chen Junling. Research on technological innovation performance evaluation of high-tech industry in Hubei Province $[\mathrm{J}]$. Science and technology progress and countermeasures, 2013,30 (21): 128-132

[11] Yang haochang, Li Lianshui. Measurement and Enlightenment of synergy between knowledge and product innovation in high-tech enterprises [J]. Scientific research, 2018,36 (10): 1889-1895

[12] Sheng Yanwen, Ma Yanji. Evaluation and influencing factors of coupling coordination degree of regional industry, University and research innovation system [J]. Economic geography, 2017,37 (11): $10-18+36$

[13] Xu Sheng, Yang Xuelong. Research on collaborative development of innovation driven and marine industry agglomeration based on the grey relational analysis of coastal provinces and cities in China [J]. East China economic management, 2018,32 (02): 109-116

[14] Fan Decheng, Du Mingyue. Dynamic comprehensive evaluation of technological innovation capacity of high-tech industry based on TOPSIS grey relation projection method -- from the perspective of Beijing Tianjin Hebei integration [J]. Operation research and management, 2017,26 (07): 154-163

[15] Li Bing, Cao Fang, Ma Yanling. Evaluation of urban innovation ability based on grey analysis [J]. Library and information, 2012 (03): 121-124

[16] Hao Qingmin, Wu Qianyue, Ge Guofeng. Innovation and risk of Green Credit: grey relational analysis [J]. Financial theory and practice, 2016 (07): 81-85

[17] Li Ziqiong, Li Xiangdong, Chen Xiaoxue. Research on comprehensive evaluation of innovation and transformation capacity of development zones based on grey correlation degree [J]. Macroeconomic research, 2015 (12): 115-120

[18] Tang Decai, Tang Jiexin, Liu Hao. Comparison and evaluation of "new type" of manufacturing industry in Central China [J]. Industrial technology and economy, 2016,35 (06): 111-121

[19] Tong Jixin, Chen Jixing, Cai Yuancheng. Study on the evaluation of the efficiency of regional scientific and technological innovation based on the grey relation analysis -- Taking Jiangsu Province as an example [J]. Scientific and technological progress and countermeasures, 2011,28 (10): 108-110

[20] Bai Yanzhuang, Zhao Guangjie, Wang Bo, Zhang Baoyin. Grey comprehensive evaluation of technological innovation ability of enterprises [J]. Journal of Tianjin University, 2006 (S1): 288-292

[21] Jiang Wenxian. Research on the evaluation of regional scientific and technological innovation capacity in Guangdong Province [J]. Science and technology management research, 2016,36 (08): 75$79+86$

[22] Hao Xiaoyan, Liu Yuanyuan, Liang Xiaoyong. Analysis of regional technological innovation capacity and its relationship with economic growth in Inner Mongolia [J]. Scientific management research, 2010,28 (04): 21-24 + 28

[23] Wei Hong, Li hengying, Wang Xuejun. The application of grey correlation analysis in the comprehensive evaluation of the benefits of enterprise technology center $[\mathrm{J}]$. Science and technology management research, 2007 (11): 67-70

[24] Wang Fang, Wang Jingdong. Grey correlation analysis of economic development and technological progress in regional innovation in Jiangsu Province [J]. Statistics and decision making, 2005 (06): $75-76$

[25] Liu Bing, Feng Hua, Wang Haiteng, Zhang Xiaowei. Research on grey correlation evaluation of innovation output and innovation environment factors -- Taking Zhongguancun as an example [J]. Academic forum, 2016,39 (01): 49-53

[26] Zhang Jian, Li Pei. Evaluation on the integration degree of collaborative innovation of modern service industry in Beijing and Tianjin: grey relational analysis [J]. Modern finance and Economics (Journal of Tianjin University of Finance and Economics), 2016,36 (01): 13-21

[27] Jia Chunguang, Cheng Junmo, Tan Xiaoyu. Dynamic evaluation and spatial difference analysis of regional science and technology innovation capacity in Shandong Province $[\mathrm{J}]$. Science and technology management research, 2020,40 (02): 106-114

[28] Li Zheng, Zhou Lun. Grey relation comprehensive evaluation method of enterprise technological innovation capability based on AHP [J]. East China economic management, 2008 (09): 106-109
[29] Zhang Jinle, Yi Chenchen, Ge Jing. Research on Development Strategies of aerospace manufacturing industry in Western China based on Entropy Weight Grey Correlation Model [J]. Science and technology progress and countermeasures, 2015,32 (17): 77 81

[30] Yao Yanting, Chen Wanming. Research on low-carbon agriculture and technological innovation based on grey correlation model [J]. Statistics and decision making, 2014 (14): 93-96

[31] Yang Mengyuan, Yu Yiyong. Research on decision-making model of sustainable innovation opportunity for innovative enterprises [J]. Journal of Yunnan University of Finance and economics, 2018,34 (12): 96-105

[32] You Daming, Huang Xizi. Selection and evaluation of breakthrough technological innovation partners [J]. Systems engineering, 2014, 32 (03): 99-103

[33] Qian Mingxia. Analysis of the factors related to the development of China's high-tech industry and independent innovation [J]. Journal of Southeast University (PHILOSOPHY AND SOCIAL SCIENCES EDITION), 2008 (03): 34-38 + 127

[34] Pang Qinghua. Comprehensive evaluation model of enterprise technological innovation capability based on grey theory [J]. Science and technology management research, 2007 (12): 113$115+118$

[35] Qi yanru, Liu Yun, Hou Yuanyuan. Comparative study on regional innovation capability based on analysis of patent influencing factors [J]. China management science, 2013,21 (S2): 594-599

[36] Wang Fang, Tang Pengzhi, Zhou Jun. empirical research on technological innovation of high tech industry in Jiangxi Province [J]. Enterprise economy, 2009 (08): 111-113

[37] Huang Han, Zhu Yubing. An Empirical Study on the influencing factors of technological innovation output capacity in Guangxi Based on the grey relational analysis model [J]. Guangxi Social Sciences, 2013 (06): 22-24

[38] Qiu Dongfang. Grey correlation analysis of Macro Influencing Factors of agricultural R \&amp; D intensity in China [J]. East China economic management, 2013,27 (03): 29-34

[39] Yang Qingyu, Li Ming. An empirical measurement of regional independent innovation capacity based on Grey Relational Analysis -- Taking Chongqing as an example [J]. Soft science, 2011,25 (01): 91-94 + 101

[40] Wang Zhibo. Evaluation of technological innovation ability of enterprises based on AHP grey relational model [J]. Statistics and decision, 2013 (04): 51-53

[41] Li Meijuan, Chen Guohong, Chen Guolong. Research on the evaluation of industrial technological innovation ability based on the grey correlation degree [J]. Journal of Shanxi University of Finance and economics, 2008 (06): 51-57

[42] Jing Xueqing. Grey correlation analysis of technological innovation ability and economic growth in Shanghai [J]. Modern management science, 2013 (01): 6-9

[43] Changyumiao, changchangchangchun. Correlation effect of Jiangsu's marine and land industries and Countermeasures for coordinated development [J]. Regional research and development, 2012,31 (04): 34-36 + 46

[44] Huang Lucheng, Zhang Hongcai. Analysis on the relationship between manufacturing competitiveness and technological innovation capacity in Beijing [J]. Science and technology progress and countermeasures, 2005 (10): 50-51

[45] Zhao Jingfeng, Wang Yanrong. Empirical Study on the relationship between innovation culture characteristics and entrepreneurship performance of high-tech enterprises [J]. Management world, 2011 (12): 184-185

[46] Wang Zhangbao, Li Lei. Grey correlation analysis of technological innovation ability and industrial competitiveness of China's manufacturing industry $[\mathrm{J}]$. Science and technology management, 2007 (07): 38-42

[47] Song Wei, Cao Zhendong, Peng Xiaobao. Fuzzy evaluation of regional independent innovation ability based on grey correlation degree $[J]$. Journal of Beijing University of Technology (SOCIAL SCIENCE EDITION), 2010,12 (03): 66-70

[48] Li Rui, Zhou Ping. Government behavior and independent innovation: an analysis framework based on the perspective of 
supply and demand $[\mathrm{J}]$. China Science and Technology Forum, 2012 (03): 11-17

[49] Li Bozhou, Yin Shi. Research on the multi-attribute decisionmaking model of manufacturing enterprise partner selection based on consistency -- cooperative innovation perspective $[\mathrm{J}]$. Operations research and management, 2018,27 (06): 6-13

[50] Zhu Minghao, dou shuihai, Jia Ji. Analysis of the effect of China's automobile industry technology innovation policy [J]. Scientific research management, 2017,38 (07): 26-36 